\title{
Acceleració angular, tangencial i normal
}

\author{
Basili Martínez Espinet \\ IES Miquel Martí i Pol (Roda de Ter). \\ bmartine@xtec.cat
}

En aquest treball pràctic de laboratori presentem una experiència que ens permet calcular, en un cas real, les acceleracions angulars tangencials i normals de diferents objectes.

Paraules clau: acceleració angular, tangencial, normal, boles, pla inclinat

\section{Introducció}

Es tracta de deixar anar des del repòs diferents tipus de boles des del cap damunt d'un pla inclinat i mesurar el temps que tarden en fer el recorregut.

Hem de fer una hipòtesi. Es tracta de suposar que les boles roden i no llisquen (al final amb les dades de l'experiment podem comprovar si aquesta hipòtesi és raonable).

En el nostre cas, per portar-ho a terme fem servir un panell de fusta i una canaleta de plàstic (fig. 1), de les que s'utilitzen per tapar els cables elèctrics. Junts faran les funcions del pla inclinat. Les boles són d'un joc de petanca i les típiques xinel-les (figs. 2, 3 i 4).

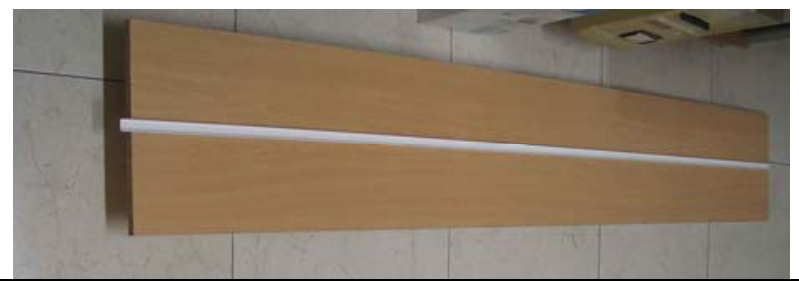

Figura 1. Perspectiva del pla inclinat.

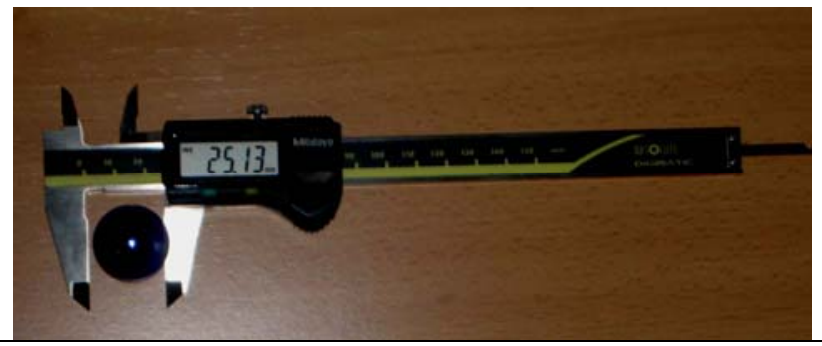

Figura 2. Mesura del diàmetre d'una bola.

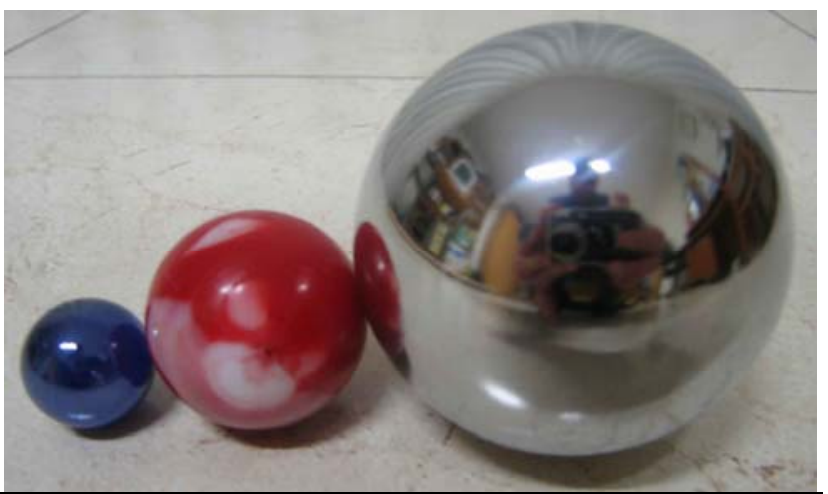

Figura 3. Les boles que fem servir.

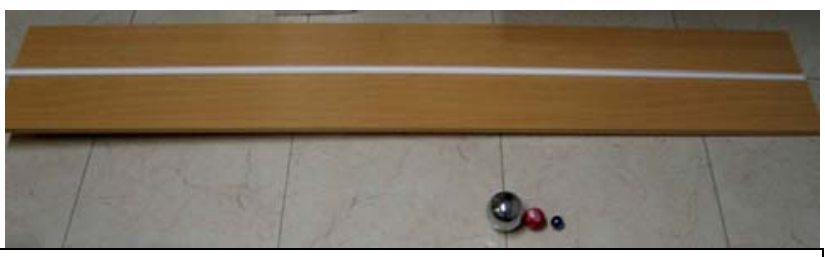

Figura 4. Les boles i el pla inclinat

\section{Objectius i orientacions a l'aula}

Aquesta pràctica està pensada per fer a física de primer de batxillerat. En aquest curs s'expliquen els conceptes d'acceleració normal, tangencial i angular, uns conceptes que a priori semblen molt teòrics i es veuen una mica llunyans.

La pràctica ajuda a entendre aquests conceptes a l'aplicar-los a un cas pràctic. La pràctica es pot fer en una hora si detallem els procediments i només demanem càlculs i conclusions. Però també 
podem plantejar els fonaments del fenomen que volem estudiar i demanar als alumnes que dissenyin la pràctica, de manera que al final s'aconsegueixin els objectius de càlcul desitjats.

Si no podem construir el pla inclinat podem mesurar els temps en el vídeo que adjuntem.

\section{Fonaments teòrics}

L'experiència consisteix en deixar anar, partint del repòs, una bola de radi conegut. Mesurem la longitud del pla i el temps que tarda a fer el recorregut, i amb aquestes tres dades podrem calcular les tres acceleracions en el punt final del pla.

També mesurarem l'altura del pla per justificar la hipòtesi que la bola efectivament roda i no llisca.

1) Aplicant la fórmula de MRUA, $\Delta x=a \cdot t^{2} / 2$ calculem $a$, que correspondrà a l'acceleració tangencial. $\Delta x$, correspon a la longitud del pla i $t$ el temps que triga a baixar-lo.

2) Aplicant $a_{t}=\alpha \cdot r$ calcularem $\alpha$, ja que coneixem el radi de la bola.

3) Aplicant $\mathrm{v}=\mathrm{a} \cdot \mathrm{t}$ i $\mathrm{a}_{\mathrm{n}}=\mathrm{v}^{2} / \mathrm{r}$ calcularem el valor de l'acceleració normal.

Per justificar la hipòtesi, hem d'aplicar el principi de conservació de l'energia (hi ha conceptes que no corresponen al nivell de batxillerat i potser no cal explicar-ho al alumnes).

L'energia inicial, que és potencial gravitatòria, es transforma en energia cinètica de translació i en energia cinètica de rotació. Hem de comprovar que les pèrdues per fregament són negligibles. Per tant:

$$
\mathrm{m} \cdot \mathrm{g} \cdot \mathrm{h}=1 / 2 \mathrm{mv} v^{2}+1 / 2 \mathrm{I} \omega^{2}
$$

on $I$ és el moment d'inèrcia de la bola i $\omega$ la seva velocitat angular. En el cas de l'esfera homogènia,

$$
I=2 / 5 \mathrm{~m} \mathrm{r}^{2}
$$

per tant, la massa surt en tots el factors i la podem obviar. Si aquesta igualtat és compleix la nostra hipòtesi serà consistent i podem assegurar una fiabilitat en els nostres resultats.

\section{Procediment experimental}

- Muntem el pla inclinat, de manera que posant-hi un llibre o un objecte a sota tingui una altura, a la part superior, al voltant dels $10 \mathrm{~cm}$. En el nostre cas, que és l'experiment que es mostra en el vídeo, l'altura és de $7 \mathrm{~cm}$. Mesurem l'altura exacta.

- Mesurem la longitud del pla, en el nostre cas mesura $180 \mathrm{~cm}$.

- Mesurem el radi de cada bola amb el peu de rei.

- Pesem les boles a la balança.

- Deixem anar la bola partint del repòs, de la part superior del pla, i mesurem el temps que triga a arribar a baix, ho fem dues vegades i fem la mitjana dels temps. Si la pràctica es fa en grups, s'ha d'insistir que en aquest punt és on cal ser més precís. Si ho fem amb molta cura els temps s'assemblen bastant fins a les dècimes de segon, i de vegades, fins a les centèsimes.

\section{Dades i resultats}

Es pot representar gràficament l'acceleració angular, respecte del radi de la bola (fig. 5) i també l'acceleració normal (fig. 6). En el nostre cas les gràfiques que hem obtingut són les següents:

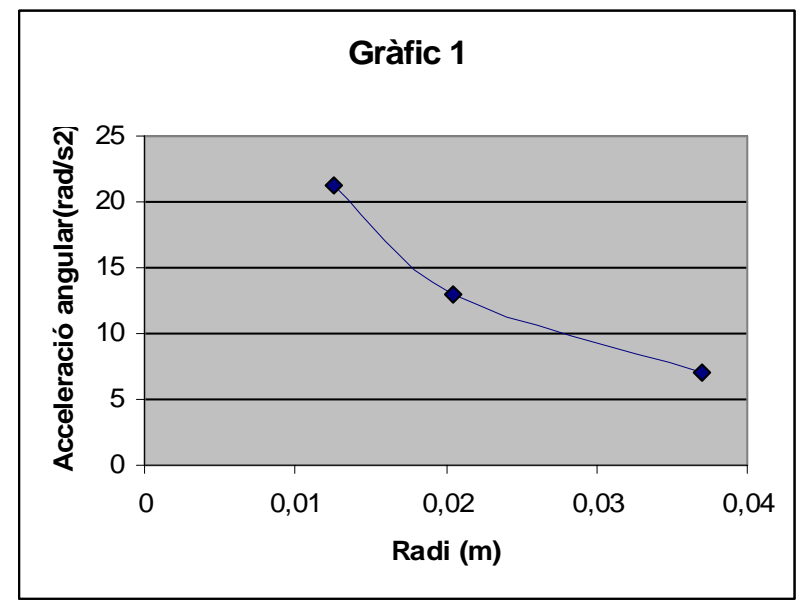

Figura 5. Gràfica de l'acceleració angular en funció

\begin{tabular}{|c|c|c|c|c|c|c|c|}
\hline Bola & $\begin{array}{c}\text { Radi } \\
\text { (m) }\end{array}$ & $\begin{array}{c}\text { Massa } \\
\text { (g) }\end{array}$ & $\begin{array}{c}\text { Temps } \\
\text { (mitjana) } \\
\text { (s) }\end{array}$ & $\begin{array}{c}\text { Acceleració } \\
\text { tangencial } \\
\left(\mathrm{m} / \mathrm{s}^{2}\right)\end{array}$ & $\begin{array}{c}\text { Velocitat } \\
\text { final } \\
(\mathrm{m} / \mathrm{s})\end{array}$ & $\begin{array}{c}\text { Acceleració } \\
\text { angular } \\
\left(\mathrm{rad} / \mathrm{s}^{2}\right)\end{array}$ & $\begin{array}{c}\text { Acceleració } \\
\text { normal } \\
\left(\mathrm{m} / \mathrm{s}^{2}\right)\end{array}$ \\
\hline Gran & 0,037 & 600 & 3,72 & 0,260 & 0,967 & 7,02 & 25,27 \\
\hline Mitjana & 0,0205 & 25 & 3,68 & 0,265 & 0,975 & 12,93 & 46,37 \\
\hline Petita & 0,0125 & 12 & 3,68 & 0,265 & 0,975 & 21,2 & 76,05 \\
\hline
\end{tabular}
del radi. 


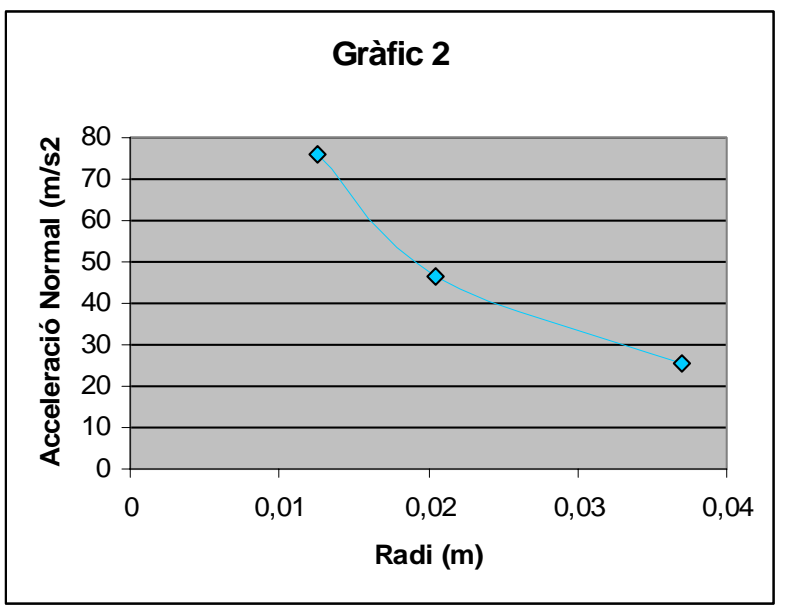

Figura 6. Gràfica de l'acceleració normal en funció del radi.

En tots dos casos les gràfiques s'haurien d'assemblar a una hipèrbola. Encara que amb tres punts no podem treure gaires conclusions, ja es veu que s'hi aproximen força.

Per comprovar que la nostra hipòtesi és consistent, apliquem la conservació de l'energia i calculem en cada cas el percentatge de l'energia inicial que perdem per fregament. Com que la massa surt en tots el termes, ja no cal que la posem. Les unitats de càlcul seran $\mathrm{J} / \mathrm{kg}$.

L'energia potencial gravitatòria que tenim inicialment es transforma en energia cinètica de translació i energia cinètica de rotació $\left(1 / 2 \cdot \mathrm{I} \omega^{2}\right)$. En el cas de l'esfera el moment d'inèrcia val $\mathrm{I}=2 / 5 \mathrm{mr}^{2}$

\section{Conclusions i qüestions}

Amb els resultats obtinguts després de fer la pràctica des de diferents altures es comprova que les diferents boles tarden el mateix temps a recórrer el pla, amb lleugeres diferencies degudes a les característiques de les seves superfícies.

Podem veure també que l'acceleració tangencial és pràcticament la mateixa per totes les boles $\mathrm{i}$ en canvi l'acceleració angular i la normal varien amb el radi de la bola.
Amb els gràfics que hem obtingut, i analitzant les fórmules, es veu que l'acceleració angular i la normal, si les representem en funció del radi, ens donaran unes corbes hiperbòliques.

També es comprova que la suposició que hem fet és força consistent, amb errors al voltant del 3 $\%$. Si utilitzéssim un objecte amb un moment d'inèrcia diferent, com per exemple un anell, observaríem diferències qualitatives importants en el temps de baixada, però aquests aspectes corresponen a un altre nivell.

A continuació proposem unes qüestions que es poden plantejar -a part dels càlculs- a l'alumnat per millorar la comprensió de l'experiència.

1) Els temps mesurats estan relacionats amb les masses de les boles?

2) Cal mesurar les masses de les boles?

3) Quantes voltes dóna cada bola per fer tot el recorregut?

4) Quina mesura de les que has fet, creus que afecta més al resultat de la pràctica?

5) Hi ha alguna relació entre l'acceleració tangencial i el radi de la bola?

6) Hi ha alguna relació entre l'acceleració angular i el radi de la bola? Quina?

7) Hi ha alguna relació entre l'acceleració tangencial i el radi de la bola? Quina?

8) Podríem utilitzar una bola de tennis per fer la pràctica?

9) Perquè creus que posem un carril al mig del pla inclinat?

10) Quines propostes faries per millorar la fiabilitat dels resultats.

\section{Bibliografia}

FÍSICA. Paul.A.Tipler. Editorial Reverté,(1978).

MECÁNICA VECTORIAL:ESTÀTICA Y DINÁMICA. Nelson, Best, McLean. Ed. Mc Graw-Hill (2004)

EXCEL FOR SCIENTISTS AND ENGINERS. E. Joseph Billo. Ed.Wiley-Interscience, (2007).

\begin{tabular}{|l|c|c|c|c|c|}
\hline Bola & $\begin{array}{c}\text { Energia } \\
\text { inicial } \\
\mathbf{( J / k g )}\end{array}$ & $\begin{array}{c}\text { Energia } \\
\text { cinètica } \\
\text { translació } \\
(\mathbf{J} / \mathbf{k g})\end{array}$ & $\begin{array}{c}\text { Energia } \\
\text { cinètica } \\
\text { rotació } \\
\mathbf{( J / k g )}\end{array}$ & $\begin{array}{c}\text { Pèrdues } \\
\text { per fric- } \\
\text { ció } \\
(\mathbf{J} / \mathbf{k g})\end{array}$ & $\begin{array}{c}\text { Percentatge } \\
\text { respecte } \\
\text { del total } \\
\mathbf{( \% )}\end{array}$ \\
\hline Gran & 0,686 & 0,467 & 0,187 & 0,032 & 4,6 \\
\hline Mitjana & 0,686 & 0,475 & 0,190 & 0,021 & 3,1 \\
\hline Petita & 0,686 & 0,475 & 0,190 & 0,021 & 3,1 \\
\hline
\end{tabular}

